Original article

\title{
Insights into the perceptions of health care providers towards clinical pharmacy services for advanced pharmaceutical care
}

\author{
Dilip Chandrasekhar $^{\mathrm{a}, * *}$, Farisa ${ }^{\mathrm{a}}$, Abel C. Mathew ${ }^{\mathrm{a}}$, Mohammed Yahiya ${ }^{\mathrm{b}}$

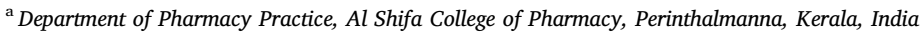 \\ ${ }^{\mathrm{b}}$ Senior Maxilofacial Surgeon, Dept of Dentistry, KIMS Alshifa Hospital, Perinthalmanna, India
}

\section{A R T I C L E I N F O}

\section{Keywords:}

Clinical pharmacy

Perceptions

Attitudes

Healthcare providers

\begin{abstract}
A B S T R A C T
Background: Clinical pharmacy is a relatively new field of practice in Indian hospital settings, the health care providers (HCPs) has scarce knowledge regarding the roles \& activities of the clinical pharmacist. The objective of this study was to determine the perceptions of health care providers towards clinical pharmacists who work on healthcare teams in terms of the potential benefits of clinical pharmacists and the current expectations of physicians and to explore the barriers that impede the clinical pharmacists' contributions from the physician's point of view.

Methodology: The study was conducted as an interventional study in a tertiary care hospital among HCPs $(n=153)$ in three phases. Pre and post-interventional phase consisted of auditing the behaviour and attitudes of HCPs about clinical pharmacy services and interventional phase consisted of developing professional recognition \& professional awareness. The statistical test was performed using the Chi-Square test and analysis of variance (ANOVA).

Results: $41.1 \%$ of the HCPs stated that they have not heard about clinical pharmacy services. A significantly higher number of physicians prefer face to a face communication system $\left(\chi^{2}=6.428\right.$, $\left.\mathrm{df}=1, \mathrm{p}<0.05\right)$ compared to nurses \& other HCPs. Lack of clinical pharmacist time was found to be the first barrier to the interprofessional relationship. $48.6 \%$ of the physicians reported that they never had open communication with the pharmacist.

Conclusion: GPs are aware of the current professional training of clinical pharmacist as being more patient orientated. However, GPs strongly disagreed that clinical pharmacist has the right to set therapeutic decisions or to maintain a complete medication profile of patients.
\end{abstract}

\section{Introduction}

Health systems are moving toward a more interprofessional approach to primary care. The role of pharmacists is expanding in primary care. There is evidence that greater collaboration between general practitioners and pharmacists can improve patient care. Joint training and co-location of practices should encourage increased collaboration between the professions. Perceptions of physician, nurses and other health care providers towards the role of clinical pharmacist are important for interprofessional practice in hospitals. Clinical pharmacy service is the practice of pharmacy as part of a multidisciplinary healthcare team directed at achieving quality use of medicine (QUM). Clinical pharmacists are practitioners who provide comprehensive medication management and related care for patients in all health care settings. They are licensed pharmacists with specialized advanced education and training who possess the clinical competencies necessary to practice in team-based, direct patient care environments. ${ }^{1}$ The World Health Organization (WHO) defines IPC as occurring when "multiple health workers from different professional backgrounds work together with patients, families, and communities to deliver the highest quality of care" (WHO, 2010). ${ }^{2}$ Clinical pharmacists work directly with doctors, nurses, other health care professionals, and patients to ensure that the medications prescribed for patients contribute to the best possible health outcomes. A clinical pharmacist is a highly trained professional who, after receiving a terminal PharmD degree or Clinical Pharmacy Diploma or Clinical pharmacy Bachelor or Clinical pharmacy Master and $\mathrm{PhD}$, may elect to continue training with one or more years of postgraduate residency and fellowship training in areas such as internal medicine, critical care, oncology, behavioural health, ambulatory care and pharmacoeconomics. Clinical pharmacists are trained to manage

\footnotetext{
* Corresponding author. Department of Pharmacy Practice, Al Shifa College of Pharmacy, Poonthavanam P.O, Perinthalmanna, Kerala, 679322, India.

E-mail address: dilipc@alshifacollegeofpharmacy.ac.in (D. Chandrasekhar).
} 
adverse drug reactions, consult on drug-drug and drug-disease interactions, and provide evidence-based drug information and pharmacoeconomic evaluations. ${ }^{3}$ The clinical pharmacist's process of care centre mainly on the following four components-assessment of the patient, Evaluation of medication therapy, Development and implementation of a plan of care and Follow-up evaluation and medication monitoring. The biggest obstacle facing pharmacists who wish to become involved in interprofessional team activities is that they are generally not perceived as "caregivers" by fellow health professional. They perceived as being so different from other professionals. Potential barriers include professional barriers, individual barriers, team barriers and physical barriers.

Clinical pharmacy is a relatively new field of practice, the health care providers have scarce knowledge regarding the roles \& activities of the clinical pharmacist in a hospital setting. As a result, they were reluctant to collaborate with clinical pharmacists in various health care aspects. It was necessary to improve the attitude of HCPs towards the clinical pharmacist by providing awareness on the necessity of having a clinical pharmacist as an integral part of the health care team \& have improved the patient care. Increased interprofessional collaboration between doctors, nurses and pharmacists can reduce the considerable medication-related morbidity and mortality.

The goal of this study was to explore the perceptions and attitudes of other health care professionals (HCPs) towards clinical pharmacy services and frequency of collaboration between general practitioners (GPs) and pharmacist from the GPs perspective.

The study anticipated to investigate the perceptions and experience of health care providers regarding the clinical role of pharmacists, measure the extent of collaboration between physicians and pharmacist by using the frequency of interprofessional collaboration instrument for general practitioners (FICI-GP) in tertiary care hospital. Other objectives also included improving patient care by coordinating the activities of various health care providers through interprofessional practice \& collaborative working relationship and to convince physicians and other health care providers to fully utilize pharmacists skills to help manage patients drug therapy.

\section{Methodology}

The study was carried out at the inpatient setting of a private tertiary care referral hospital at the Malabar region of Kerala. It was conducted as an interventional study that aims at exploring the perceptions and attitudes of other health care professionals (HCPs) towards clinical pharmacy services and frequency of collaboration between general practitioners (GPs) and pharmacist from the GPs perspective. The study included physicians, nurses, dietitians, physiotherapist, quality control department professionals and other medical and paramedical interns who were worked in clinical departments at the hospital throughout the study period. Visiting physicians \& professionals who worked in the pharmacy department were excluded from the study. The study was conducted through three phases.

The first phase included an audit period for the evaluation of perceptions, attitudes, and experiences \& expectations of HCPs towards Clinical pharmacy services. It was done through a self-administered questionnaire and a Frequency of interprofessional collaboration instrument for GPs (FICI-GP). Both closed and open questions were included in the questionnaire and were intended to collect the information from HCPs such as professional demographics, perception and attitude questions towards clinical pharmacy services, experience and expectation questions from the side of clinical pharmacist and practice questions. Frequency of Interprofessional Collaboration Instrument for GPs (FICI-GP) developed by Connie Van et al. ${ }^{4}$ was used for evaluating GPs attitudes towards collaboration with the pharmacist. The second phase was an interventional phase in which developing professional recognition \& professional awareness was done. This stage aimed at increasing clinical pharmacist's recognition among health care providers through communication with physicians, nurses and other HCPs to inform them of our interest in collaboration, discussion of ideas with physicians to judge their interest, identification of pharmacy services that can complement the healthcare providers practice along with meeting patient needs. This stage focused on conducting an awareness program to the health care professionals about clinical pharmacy services and role of clinical pharmacist by visiting each nursing stations, physicians and other clinical departments in the hospital. This phase also emphasized on interactions of a discrete nature such as identifying adverse drug interactions, answering drug information queries, medication history interview, patient counselling on safe and appropriate use of medicine, patient care rounds and other health promotion activities. The third re-audit phase was performed for a period of 1-3 months to assess the perceptions of health care providers after an intervention (Developing Professional Recognition \& Professional Awareness) by distributing feedback questionnaire. The same questionnaires, comprising of the Frequency of Interprofessional Collaboration Instrument for GPs (FICI-GP) \& self-administered questionnaire were distributed by personal interview to the healthcare professionals. The statistical test was performed using Chi-Square test to calculate the homogeneity of the proportion of each group of participant responses regarding with each statement in the questionnaire and Analysis of variance technique (ANOVA) for comparing attitudes of different group professionals with countries of qualification obtained, years of experience \& area of practice.

\section{Results}

In the study out of 180 questionnaires distributed, 153 were completed and returned by HCPs. (Response rate $=85 \%$ ). After the intervention, when the feedback questionnaires were distributed only 147 was returned, due to the resignation of some professionals. 67 of the 153 respondents (43.8\%) were aged between 21 and 25 years. $19.6 \%$ of the respondents belonged to the age group 26-30 $(n=30)$, followed by age group $31-35$ years which constitutes $16.3 \%(n=25)$. A minimum number of professionals $(n=3)$ were found in the age group 61-65 years which makes $1.9 \%$.

Out of 153 participants, female constituted 68.6\% $(\mathrm{n}=105)$ and $31.4 \%$ ( $\mathrm{n}=48$ ) were constituted by males. The age of the subjects varies from 21 to 65 years with a mean age of 30.78 years. The standard deviation was 9.67 years. The questionnaire was completed by 153 HCPs, being $22.9 \%$ of physicians $(n=35), 68.6 \%$ of nurses $(n=105)$ and $8.5 \%$ of other professionals $(\mathrm{n}=13)$. The professionals were categorized into different positions for better assessment of HCPs perspectives regarding the role of a clinical pharmacist. In physicians, major participation was by the consultant physicians $(8.5 \%, \mathrm{n}=13)$ followed by 10 junior registrars $(6.5 \%) \&$ a minimum number of physicians from the senior registrar $(7.8 \%, \mathrm{n}=12)$. In nurses, majority of participants were staff nurses $(17.6 \%, \mathrm{n}=27)$ \& nursing interns $(17.6 \%, \mathrm{n}=27)$ and least number of participant were nursing superintendent which makes $1.9 \%(n=3)$. Professionals from different departments of hospital were included in the study of which general medicine comprised $22.2 \%(\mathrm{n}=34)$ followed by surgery $(16.3 \%$, $\mathrm{n}=25)$, neurology $(6.5 \%, \mathrm{n}=10)$, cardiology $(7.2 \%)$, pediatrics (8.5\%), gynecology (7.8\%), nephrology (4.6\%), quality control $(1.9 \%)$ \& others $(24.8 \%)$.

Of the total, $74.5 \%$ of professionals reported that they obtained their professional degree or qualification from India while $7.8 \%$ and $11.1 \%$ of respondents stated that their professional qualification was obtained from USA \& other countries respectively. A minimum number of professionals ( $n=3,1.9 \%$ ) obtained the qualification from UAE. Maximum number of physicians $(\mathrm{n}=12,34 \%)$ obtained the qualification from USA \& minimum ( $=3,6 \%)$ from UAE. The qualification year of professionals was categorized into different groups for a better comparison of the year of qualification and their attitude towards clinical pharmacy services. The number of professionals got qualified in 
Table: 1

Professional's attitudes towards the role of clinical pharmacist.

\begin{tabular}{|c|c|c|c|c|c|c|c|c|}
\hline \multirow[t]{3}{*}{ FUNCTIONS OF CLINICAL PHARMACIST } & \multicolumn{4}{|c|}{ BEFORE } & \multicolumn{4}{|c|}{ AFTER } \\
\hline & \multicolumn{2}{|l|}{ YES } & \multicolumn{2}{|l|}{ NO } & \multicolumn{2}{|l|}{ YES } & \multicolumn{2}{|l|}{ NO } \\
\hline & $\mathrm{N}$ & $\%$ & $\mathrm{~N}$ & $\%$ & $\mathrm{~N}$ & $\%$ & $\mathrm{~N}$ & $\%$ \\
\hline A clinical pharmacist is an integral part of the clinical ward team & 93 & 60.8 & 60 & 39.1 & 120 & 81.6 & 27 & 18.4 \\
\hline Clinical pharmacist have the right to set therapeutic decisions & 50 & 32.7 & 103 & 67.3 & 69 & 46.9 & 78 & 53.0 \\
\hline Clinical pharmacist activities caused any disturbance to your duties & 28 & 18.3 & 125 & 81.6 & 19 & 12.9 & 128 & 87.0 \\
\hline Clinical pharmacist have role in Indian hospital scenario & 125 & 81.7 & 28 & 18.2 & 136 & 92.4 & 11 & 7.5 \\
\hline Willing to participate in educational program on drug related aspects & 138 & 90.1 & 15 & 9.8 & 139 & 94.5 & 8 & 5.3 \\
\hline Willing work along with clinical pharmacist for better patient care & 127 & 83.0 & 26 & 17.0 & 134 & 91.1 & 13 & 8.8 \\
\hline
\end{tabular}

the year of 2011-2015 ( $\mathrm{n}=88$ ) which constitutes $57.5 \%$ while only one subject was found to obtain the qualification during 1986-1990 which makes $0.65 \%$. Year of experience in the health care system shows professionals with $<1$-year experience as major $(41.2 \%)$ and $>15$ years as minor $(9.15 \%)$.

The perceptions of professionals towards clinical pharmacy services were assessed using three statements regarding the various services provided by the clinical pharmacy department and have been summarized in Table 1 . A total of $41.1 \%$ of the participants stated that they have not heard about clinical pharmacy services, while after providing intervention it changed to $13.7 \%$. $85.6 \%$ of the HCPs were interested in knowing more about clinical pharmacy services and after providing the intervention a slight change was observed (96.6\%), while no statistical change was observed. When asked about drug information services, $53.6 \%$ of them gave a negative response which improved after providing the awareness classes and a statistically significant difference was observed among the nurses $\left(\chi^{2}=21.441\right.$, $\left.\mathrm{df}=1, \mathrm{p}<0.001\right)$.

Before providing the intervention, $89.6 \%$ of the participants indicated that patient care rounds were not performed by the clinical pharmacists whilst after the intervention, a statistically significant change was observed $\left(\chi^{2}=8.067, \mathrm{df}=1, \mathrm{p}<0.01\right)$. Among all the HCPs it was nurses who showed a significant improvement in the responses $\left(\chi^{2}=11.904, \mathrm{df}=1, \mathrm{p}<0.001\right)$. A significantly higher number of physicians and nurses were found to have changed their perception regarding the clinical pharmacist's suggestions in optimizing drug prescriptions and administration $\left(\chi^{2}=6.25\right.$, $\left.\mathrm{df}=1, \mathrm{p}<0.05\right)$ and $\left(\chi^{2}=5.261, \mathrm{df}=1, \mathrm{p}<0.05\right)$ respectively. A statistically significant difference was seen in the number of nurses before and after providing the intervention $\left(\chi^{2}=19.463, \mathrm{df}=1, \mathrm{p}<0.001\right)$ with a higher number of them agreeing that clinical pharmacists are involved in detection and reporting of ADR on a daily basis. After the intervention, a significantly higher number of nurses believed that clinical pharmacists provide drug information to HCPs on a daily and monthly basis $(\mathrm{p}<0.05)$ whereas a statistically significant number of the physicians said they perform it daily ( $\mathrm{p}<0.01$ ). In case of drug education and health promotion activities by pharmacists, before the intervention, the number of nurses who responded that it was not performed were significantly higher than those with the same response after providing the intervention $\left(\chi^{2}=4.9, \mathrm{df}=1, \mathrm{p}<0.05\right)$. Even after providing interventions there was no statistically significant change in the perception of health care providers regarding the patient counselling and medication history interview, except physicians, who showed a significant difference in the number of them after the intervention $\left(\chi^{2}=6.231, \mathrm{df}=1, \mathrm{p}<0.05\right)$.

No significant change was brought about in the attitudes of HCPs towards the functions of a clinical pharmacist as an integral part of the clinical ward team $(p>0.05)$ (Table No-1). Experiences of professionals with clinical pharmacist show that a significantly higher number of nurses experienced favours from a clinical pharmacist after intervention than before $\left(\chi^{2}=20.876\right.$, $\left.\mathrm{df}=1, \mathrm{p}<0.001\right)$ while compared to physicians \& other HCPs. (Table 2).

Table 3 shows the data on expectations of professionals with the clinical pharmacist before and after interventions. A significantly higher number of nurses had a neutral response towards the following statements: pharmacists are a professional expert on drugs $\left(\chi^{2}=4.0, \mathrm{df}=1, \mathrm{p}<0.05\right)$, pharmacists should provide patient counselling on the safe \& appropriate use of drugs $\left(\chi^{2}=9.0, \mathrm{df}=1\right.$, $\mathrm{p}<0.001$ ).A higher number of nurses disagreed to the statement "pharmacists should perform detection and reporting of drug interactions and ADR" before than after intervention $\left(\chi^{2}=3.846\right.$, df $=1$, $\mathrm{p}<0.05)$ among other professionals. There was no significant difference in the expectation of all the 3 categories of staff $(\mathrm{p}>0.05)$ before \& after providing intervention regarding clinical pharmacist participation in clinical rounds.

The significantly higher number of physicians prefer face to a face communication system $\left(\chi^{2}=6.428\right.$, df $\left.=1, \mathrm{p}<0.05\right)$ compared to nurses \& other HCPs. Data obtained show a p-value more than 0.05 , thus it was concluded that none of the 3 groups i.e. physicians, nurses \& others prefers communication with phone. A statistically significant number of nurses prefer e-mail compared to other communication systems ( $\left.\chi^{2}=6.943, \mathrm{df}=1, \mathrm{p}<0.05\right)$. No statistical significance was found in all the 3 types of staff favouring no communication.

Data obtained on professional barriers to inter-professional relationship perceived by professionals gives a p-value more than 0.05 , thus it was concluded that none of the 3 types of professionals was of the opinion that lack of clinical pharmacist time causes the barrier to the interprofessional relationship. The significantly higher number of physician \& nurses were unaware of who the clinical pharmacist was ( $\mathrm{p}<0.001$ ) compared to other HCPs (Fig. 1).

Table 4 represents the data collected on the collaboration of physicians with a clinical pharmacist. $48.6 \%$ of the physicians reported that they never had open communication with the pharmacist. Though there was no statistically significant change after providing intervention, a slight change was observed i.e. only $9.1 \%$ of them said there was no communication with the pharmacist. Before the intervention, only $17.1 \%$ of the physicians indicated that they were informed about new products and services by the pharmacist 3-4 times, which improved to $24.2 \%$ after intervention which is not a statistically significant change ( $\mathrm{p}>0.05)$.

Country of qualification obtained can be correlated to the attitudes of physicians towards clinical pharmacy services. A significantly higher number of physicians who obtained a qualification from the USA \& UK, they agree with the clinical pharmacist as an integral part of the medical ward team $(\mathrm{p}<0.01)$. With respect to clinical pharmacist's right to set therapeutic decision, significantly higher number of physicians trained in the USA agrees with this $(\mathrm{p}<0.01)$ when compared to physicians who obtained a qualification from India ( $p<0.001)$.

A significantly higher number of professionals who have experience of 1-5 years reported that clinical pharmacist is an integral part of the clinical ward team $(\mathrm{p}<0.01)$. Among the study participants, a significantly higher number of professionals with an experience of $<1$ year \& 6-10 years answered that clinical pharmacist has the right to set therapeutic decision ( $p<0.001$ ) (Fig. 2). In medicine \& nephrology, a statistically significantly higher number of professionals have a positive 
Table 2

Experiences of professionals with the clinical pharmacist.

\begin{tabular}{|c|c|c|c|c|c|c|c|c|}
\hline \multirow[t]{3}{*}{ STATEMENTS } & \multicolumn{4}{|c|}{ BEFORE } & \multicolumn{4}{|c|}{ AFTER } \\
\hline & \multicolumn{2}{|c|}{ YES } & \multicolumn{2}{|l|}{ NO } & \multicolumn{2}{|l|}{ YES } & \multicolumn{2}{|l|}{ NO } \\
\hline & $\mathrm{N}$ & $\%$ & $\mathrm{~N}$ & $\%$ & $\mathrm{~N}$ & $\%$ & $\mathrm{~N}$ & $\%$ \\
\hline Experienced any favors from clinical pharmacist & 49 & 32.0 & 104 & 67.9 & 108 & 73.4 & 39 & 26.5 \\
\hline Clinical pharmacist is reliable source of drug information & 49 & 31.9 & 104 & 67.9 & 115 & 78.2 & 32 & 21.7 \\
\hline Routinely counselling patients on the use of their medications & 52 & 34 & 101 & 65.9 & 87 & 59.2 & 60 & 40.7 \\
\hline Help in administrating medicine & 36 & 23.6 & 117 & 74.4 & 72 & 49.0 & 75 & 50.9 \\
\hline Help in checking vitals & 19 & 12.4 & 134 & 87.5 & 38 & 25.9 & 109 & 74.1 \\
\hline Inform about more cost effective alternatives to the drugs & 34 & 22.1 & 119 & 77.7 & 60 & 40.9 & 87 & 59.1 \\
\hline Reported any drug-related problems like ADRs and medication error & 45 & 29.4 & 108 & 70.6 & 60 & 40.8 & 87 & 59.1 \\
\hline Gained any drug related aspects from clinical pharmacist & 42 & 27.4 & 111 & 72.6 & 99 & 67.2 & 48 & 32.6 \\
\hline Clinical pharmacist is an important in team work \& interprofessional patient care & 73 & 47.6 & 80 & 52.3 & 121 & 82.3 & 26 & 17.6 \\
\hline
\end{tabular}

response ( $p<0.01$ ) to the question of whether a clinical pharmacist is an integral part of the clinical ward team. A significantly higher number of professionals who practice in the area of surgery \& neurology, disagree with respect to question that clinical pharmacist has the right set therapeutic decision $(\mathrm{p}<0.01)$.

Professionals, irrespective of their departments, have not experienced any disturbances due to clinical pharmacist activities
( $p<0.01$ ). A significantly higher number of professionals who worked in all departments have the opinion that clinical pharmacy has a role in Indian hospital scenario ( $p<0.01$ ). Except for quality control department, professionals who practice in all other area indicated that they are willing to participate in an educational program on drug-related aspects \& work along with clinical pharmacist for better patient care $(\mathrm{p}<0.01)$.

Table 3

Expectations of professionals with the clinical pharmacist.

\begin{tabular}{|c|c|c|c|c|c|c|c|c|c|c|c|c|c|}
\hline \multirow[t]{3}{*}{ STATEMENTS } & \multirow[t]{3}{*}{ PROFESSION } & \multicolumn{6}{|c|}{ BEFORE } & \multicolumn{6}{|c|}{ AFTER } \\
\hline & & \multicolumn{2}{|c|}{ Agree } & \multicolumn{2}{|c|}{ Neutral } & \multicolumn{2}{|c|}{ Disagree } & \multicolumn{2}{|c|}{ Agree } & \multicolumn{2}{|c|}{ Neutral } & \multicolumn{2}{|c|}{ Disagree } \\
\hline & & $\mathrm{N}$ & $\%$ & $\mathrm{~N}$ & $\%$ & $\mathrm{~N}$ & $\%$ & $\mathrm{~N}$ & $\%$ & $\mathrm{~N}$ & $\%$ & $\mathrm{~N}$ & $\%$ \\
\hline \multirow[t]{4}{*}{ Professional experts on the drugs } & Physician & 26 & 16.9 & 4 & 2.6 & 5 & 3.3 & 30 & 20.4 & 1 & 0.7 & 2 & 1.3 \\
\hline & Nurse & 71 & 46.4 & 12 & 7.8 & 22 & 14.3 & 86 & 58.5 & 4 & 2.7 & 13 & 8.8 \\
\hline & Others & 9 & 5.8 & 1 & 0.7 & 2 & 1.3 & 10 & 6.8 & 0 & 0.0 & 1 & 0.7 \\
\hline & Total & 106 & 69.1 & 17 & 11.1 & 29 & 18.9 & 126 & 85.7 & 5 & 3.4 & 16 & 10.8 \\
\hline \multirow[t]{4}{*}{ Patient counselling on the safe \& appropriate use of drugs } & Physician & 22 & 14.3 & 5 & 3.3 & 8 & 5.2 & 28 & 19.0 & 2 & 1.3 & 3 & 2.0 \\
\hline & Nurse & 80 & 52.3 & 14 & 9.2 & 11 & 7.1 & 93 & 63.3 & 2 & 1.7 & 8 & 5.4 \\
\hline & Others & 7 & 4.6 & 4 & 2.6 & 2 & 1.3 & 9 & 6.1 & 0 & 0.0 & 2 & 1.3 \\
\hline & Total & 109 & 71.2 & 23 & 15.1 & 21 & 13.6 & 130 & 88.4 & 4 & 3.0 & 13 & 8.7 \\
\hline \multirow[t]{4}{*}{ Assist in designing drug therapy treatment plans for patients } & Physician & 25 & 16.3 & 4 & 2.6 & 6 & 3.9 & 30 & 20.4 & 1 & 0.7 & 2 & 1.3 \\
\hline & Nurse & 66 & 43.1 & 22 & 14.4 & 17 & 11.1 & 89 & 60.5 & 3 & 2.0 & 11 & 7.4 \\
\hline & Others & 10 & 6.5 & 1 & 0.7 & 2 & 1.3 & 10 & 6.8 & 0 & 0.0 & 1 & 0.7 \\
\hline & Total & 101 & 65.9 & 27 & 17.7 & 25 & 16.3 & 129 & 87.7 & 4 & 3.0 & 14 & 9.4 \\
\hline \multirow[t]{4}{*}{ Monitor patients response to drug therapy and encounters any drug related problems } & Physician & 26 & 16.9 & 2 & 1.3 & 7 & 4.6 & 31 & 21.1 & 0 & 0.0 & 2 & 1.7 \\
\hline & Nurse & 81 & 52.9 & 13 & 8.4 & 11 & 7.1 & 96 & 65.3 & 1 & 0.7 & 6 & 4.1 \\
\hline & Others & 8 & 5.2 & 2 & 1.3 & 3 & 1.9 & 9 & 6.1 & 1 & 0.7 & 1 & 0.7 \\
\hline & Total & 115 & 75.0 & 17 & 11.0 & 21 & 13.6 & 136 & 92.5 & 2 & 1.4 & 9 & 6.5 \\
\hline \multirow[t]{4}{*}{ Perform detection \& reporting of drug interaction \& ADRs } & Physician & 27 & 17.6 & 3 & 1.9 & 5 & 3.3 & 32 & 21.8 & 0 & 0.0 & 1 & 0.7 \\
\hline & Nurse & 79 & 51.6 & 8 & 5.2 & 18 & 11.8 & 91 & 61.9 & 4 & 2.7 & 8 & 5.4 \\
\hline & Others & 9 & 5.9 & 2 & 1.3 & 2 & 1.3 & 9 & 6.1 & 0 & 0.0 & 2 & 1.3 \\
\hline & Total & 115 & 75.0 & 13 & 8.4 & 25 & 16.3 & 132 & 89.8 & 4 & 3.0 & 11 & 7.4 \\
\hline \multirow[t]{4}{*}{ Participation on clinical rounds } & Physician & 27 & 17.6 & 2 & 1.3 & 6 & 3.9 & 29 & 19.7 & 1 & 0.7 & 3 & 2.0 \\
\hline & Nurse & 59 & 38.6 & 19 & 12.4 & 27 & 17.6 & 68 & 46.3 & 16 & 10.9 & 19 & 12.9 \\
\hline & Others & 6 & 3.9 & 2 & 1.3 & 5 & 3.3 & 8 & 5.4 & 2 & 18.2 & 1 & 0.7 \\
\hline & Total & 92 & 60.1 & 23 & 15.0 & 38 & 24.8 & 105 & 71.4 & 19 & 13.3 & 23 & 15.6 \\
\hline \multirow[t]{4}{*}{ Provide information about cost effectiveness \& medication efficacy } & Physician & 31 & 20.3 & 1 & 0.7 & 3 & 1.9 & 32 & 21.8 & 0 & 0.0 & 1 & 0.7 \\
\hline & Nurse & 73 & 47.7 & 13 & 8.5 & 19 & 12.4 & 86 & 58.5 & 3 & 2.0 & 14 & 9.5 \\
\hline & Others & 8 & 5.2 & 3 & 1.9 & 2 & 1.3 & 8 & 5.4 & 1 & 0.7 & 2 & 1.7 \\
\hline & Total & 112 & 73.2 & 17 & 11.1 & 24 & 15.6 & 126 & 85.7 & 4 & 3.0 & 17 & 11.9 \\
\hline \multirow[t]{4}{*}{ Enhance patient compliance } & Physician & 29 & 18.9 & 2 & 1.3 & 4 & 2.6 & 30 & 20.4 & 1 & 0.7 & 2 & 1.3 \\
\hline & Nurse & 65 & 42.5 & 16 & 10.5 & 24 & 15.7 & 69 & 46.9 & 18 & 12.3 & 16 & 10.9 \\
\hline & Others & 8 & 5.2 & 3 & 1.9 & 2 & 1.3 & 8 & 5.4 & 2 & 1.4 & 1 & 0.7 \\
\hline & Total & 102 & 66.6 & 21 & 13.7 & 30 & 19.6 & 107 & 72.7 & 21 & 14.4 & 19 & 12.9 \\
\hline \multirow[t]{4}{*}{ Can improve quality of health care } & Physician & 28 & 18.3 & 3 & 1.9 & 4 & 2.6 & 27 & 18.4 & 2 & 1.4 & 4 & 2.7 \\
\hline & Nurse & 71 & 46.4 & 12 & 7.8 & 22 & 14.4 & 82 & 55.8 & 9 & 6.1 & 12 & 8.1 \\
\hline & Others & 7 & 4.6 & 3 & 1.9 & 3 & 1.9 & 9 & 6.1 & 1 & 0.7 & 1 & 0.7 \\
\hline & Total & 106 & 69.3 & 18 & 11.6 & 29 & 18.9 & 118 & 80.3 & 12 & 8.2 & 17 & 11.5 \\
\hline \multirow[t]{4}{*}{ Increasing needs of clinical pharmacist in our hospital settings } & Physician & 29 & 18.9 & 3 & 1.9 & 3 & 1.9 & 28 & 19.0 & 2 & 1.4 & 3 & 2.0 \\
\hline & Nurse & 67 & 43.8 & 22 & 14.4 & 16 & 10.5 & 86 & 58.5 & 10 & 6.8 & 7 & 4.8 \\
\hline & Others & 9 & 5.9 & 2 & 1.3 & 2 & 1.3 & 9 & 6.1 & 1 & 0.7 & 1 & 0.7 \\
\hline & Total & 105 & 68.6 & 27 & 17.6 & 21 & 13.7 & 123 & 83.6 & 13 & 8.7 & 11 & 7.5 \\
\hline
\end{tabular}




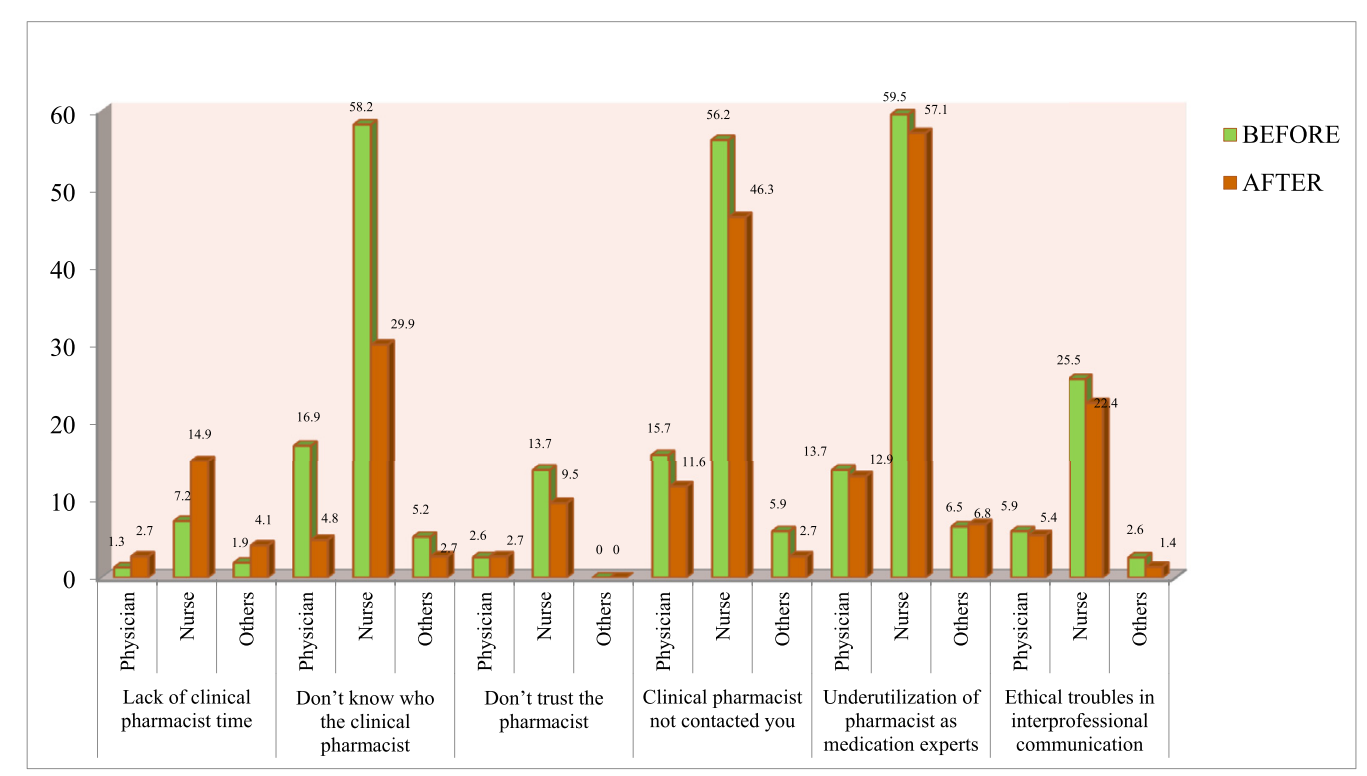

Fig. 1. -Barrier to interprofessional relationship perceived by professionals.

\section{Discussion}

This study attempted to give a partial picture of the implementation of clinical pharmacy services in tertiary care hospitals. Before providing the intervention, a total of 153 filled questionnaires were returned representing 153 of $180 \mathrm{HCPs}$ to whom the questionnaire was distributed (response rate $85 \%$ ), with a female dominance (68.6\%) while after intervention only 147 HCPs were observed due to the resignation of some professionals. The study population was less when compared to the studies of Nirmeen. A.sabry \& Samad.F.Farid, ${ }^{5}$ Manal Zaidan et al., ${ }^{6}$ Saja Almazrou et al. ${ }^{7}$ \& Niurka Maria Dupotey Varela et al. ${ }^{8}$ Studies from Abu-Gharbieh et al. ${ }^{9}$ in United Arab Emirates \&Wilbur et al. ${ }^{10}$ in Qatar found that more than half of the respondents have heard about clinical pharmacy services \& the majority of the participants were interested in knowing more about clinical pharmacy services which coincide with the results of the study. In general, before the intervention, physicians \& nurses showed very low perception about the performance of clinical functions of pharmacists. This may be due to the fact that the health care professionals working in our hospital were not familiar with the clinical activities of pharmacist before providing intervention. Significant changes were found in the perception of health care providers after providing interventions. Before providing the intervention, the majority of the participants indicated that patient care rounds \& optimizing drug prescriptions and administration were not performed by the clinical pharmacists. This result was consistent with the results of a study conducted by Niurka Maria Dupotey Varela et al. ${ }^{8}$ in Santiago de Cuba \&Manal Zaidan et al. ${ }^{6}$ in Qatar. A higher number of physicians and nurses were found to have changed their perception regarding the clinical pharmacist's suggestions in optimizing drug prescriptions and administration \& participation in patient care rounds at the hospital after providing the intervention. From physicians' and nurses' perspectives, the most common activities carried out by clinical pharmacists were detection and reporting of adverse drug reactions on a daily basis in both before and after providing the intervention. This result coincides with the results of the study carried out by Niurka Maria Dupotey Varela et al. ${ }^{8}$ \& Osama Mohamed Ibrahim et al. ${ }^{11}$ in the United Arab Emirates. In case of drug education and health promotion activities by pharmacists, before intervention the number of nurses providing a negative response compared to physicians \& other HCPs which are in agreement with the results of studies conducted by Bilal et al. ${ }^{12}$ in Ethiopia \& Deborah V. Kelly et al. ${ }^{13}$ in Canada. Even after providing interventions, except physicians, there was no change in the perception of other health care providers regarding the patient counselling and medication history interview. On the other hand, pharmaceutical care in our hospital has usually developed at an experimental level, not at a practice level. There were structural aspects under analysis that limit the development and delivery of services such as pharmacotherapy follow-up. For instance, pharmacies do not have a private room for patients' consultations; moreover, they have a small number of pharmacists dedicated to clinical functions. In this study, about $90 \%$ of professionals were willing to participate in the educational program on drug-related aspects\& to working along with clinical pharmacist for better patient care which is comparable with the results of the studies carried out by Abu-Gharbieh et al. ${ }^{9}$ in UAE, N. M. D. Varela et al. ${ }^{8}$ in Santiago de Cuba and Roland Nnaemeka Okoro et al. ${ }^{14}$ in the University of Maiduguri Teaching Hospital (UMTH). The study reveals the experience of health care professionals with clinical pharmacists. Participants experienced that pharmacists were a reliable source of general drug information (32\%) and important in teamwork \& interprofessional patient care $(48 \%)$. Only a few HCPs agreed that they gained enough knowledge about drugs from the clinical pharmacist. Physicians' experiences were neutral toward pharmacists counselling patients on the safe and appropriate use of their medications. This has become consistent with the results of Manal Zaidan et $a l .{ }^{6}$ in UAE \& Nirmeen A. Sabry and Samar F. Farid ${ }^{5}$ in Egypt. More physicians were expecting pharmacists designing drug therapy and assisting patients in selecting appropriate non-prescription medications than those who were not. Similar to these findings Manal Zaidan et al. ${ }^{6}$ in Qatar\& Xin Li et al. ${ }^{15}$ in China reported that physicians appeared to have high expectations of pharmacists as knowledgeable drug therapy experts and expect them to educate patients about the safe and appropriate use of medications.

In this study, professional's preferred communication with the clinical pharmacist was accessed for developing the interprofessional collaboration between the health care providers in the hospital. Regarding sharing patient information, physicians preferred face to face communication over phone or email system correspondence with nurses \& other HCPs. Nurses preferred E-mail or a face to face communication system. Face-to-face contact\& E-mail was selected to be the best method of communications by physicians, nurses \& other HCPs to enhance their collaboration with clinical pharmacists. Compared to the finding of Deborah V. Kelly et al. ${ }^{13}$ in Canada, professionals preferred electronic transfer of information with a clinical pharmacist.

This study showed that health care professionals generally agreed regarding barriers to collaborative practice and establishing 
professional relationships. The most important barriers perceived by professionals in establishing a relationship with pharmacists were: "I don't know who the pharmacist is"; "The pharmacist has not contacted me"; "lack of time of physicians and nurses" and lack of time of the pharmacist. Insufficient communication between pharmacists and other professionals in hospitals occurs for several reasons. One barrier that has been cited is pharmacists' expressed lack of confidence in their ability to persuade physicians to accept their recommendations. Another possible cause is ineffective or needless communication initiated by pharmacists, which makes physicians less willing to listen to pharmacists during future interactions (Ranelli, Biss, 2000). ${ }^{16}$ Comparison of the country of qualification with the attitude of HCPs indicated that physician who obtained a qualification from USA \& UK have a better understanding on the role of a clinical pharmacist when compared to physicians who were trained in India \& other countries. Similar results have also been reported in other studies such as Manal Zaidan et al., ${ }^{6}$ Hassali MA et al. ${ }^{17}$ in Malaysia \& Abu-Gharbieh et al. ${ }^{9}$

No significant trend was observed between years of experience of the HCPs and their attitudes regarding the role of clinical pharmacists which is in concordant with the study conducted by Nirmeen A. Sabry and Samar F. Farid ${ }^{5}$ among the role of clinical pharmacists as perceived by Egyptian physicians. Although similar results were detected in Qatar, younger American physicians have expressed higher expectations of pharmacy practice and collaboration when compared with their senior colleagues but, this was due to the fact that clinical pharmacy is still a new concept in our hospital that has still not reached the wide majority of physicians \& other HCPs practising in the Indian healthcare system., a relatively small sample size (153 professionals) was studied. However, to the best of our knowledge, this is the first time physician's perception of clinical pharmacy is being studied in India. Secondly, all the professionals who completed the questionnaire practised in our hospital. Thus, this research provides no data about rural areas \& other hospitals where clinical pharmacy services are less common. Thirdly, a parallel study exploring pharmacist training was not conducted. In addition, the re-audit of the study was done shortly after providing the intervention to the health care professionals about clinical pharmacy services and role of clinical pharmacist by visiting each nursing stations, physicians and other clinical departments in the hospital. Thus, health care providers might have limited time to observe and evaluate the clinical pharmacists' performance which could possibly undermine the performance of the graduate. All studies similar to this study were only an observational survey. In this study, an awareness class about clinical pharmacy services was provided and a re-audit was performed to assess the perceptions of health care providers by distributing feedback questionnaire.

\section{Conclusion}

GPs are aware of the current professional training of clinical pharmacist as being more patient orientated. The physicians are willing to collaborate with the clinical pharmacist in monitoring drug therapy and they could recognize the importance of pharmacist's participation in clinical ward rounds and their role as educators and advisors for patients on the safe use of drugs. However, GPs strongly disagreed that clinical pharmacist has the right to set therapeutic decisions or to maintain a complete medication profile of patients. Physicians who obtained a qualification from USA \& UK have better discernment on the role of a clinical pharmacist when compared to physicians who were trained in India \& other countries.

\section{Funding}

The authors have not declared a specific grant for this research from any funding agency in the public, commercial or not-for-profit sectors. 


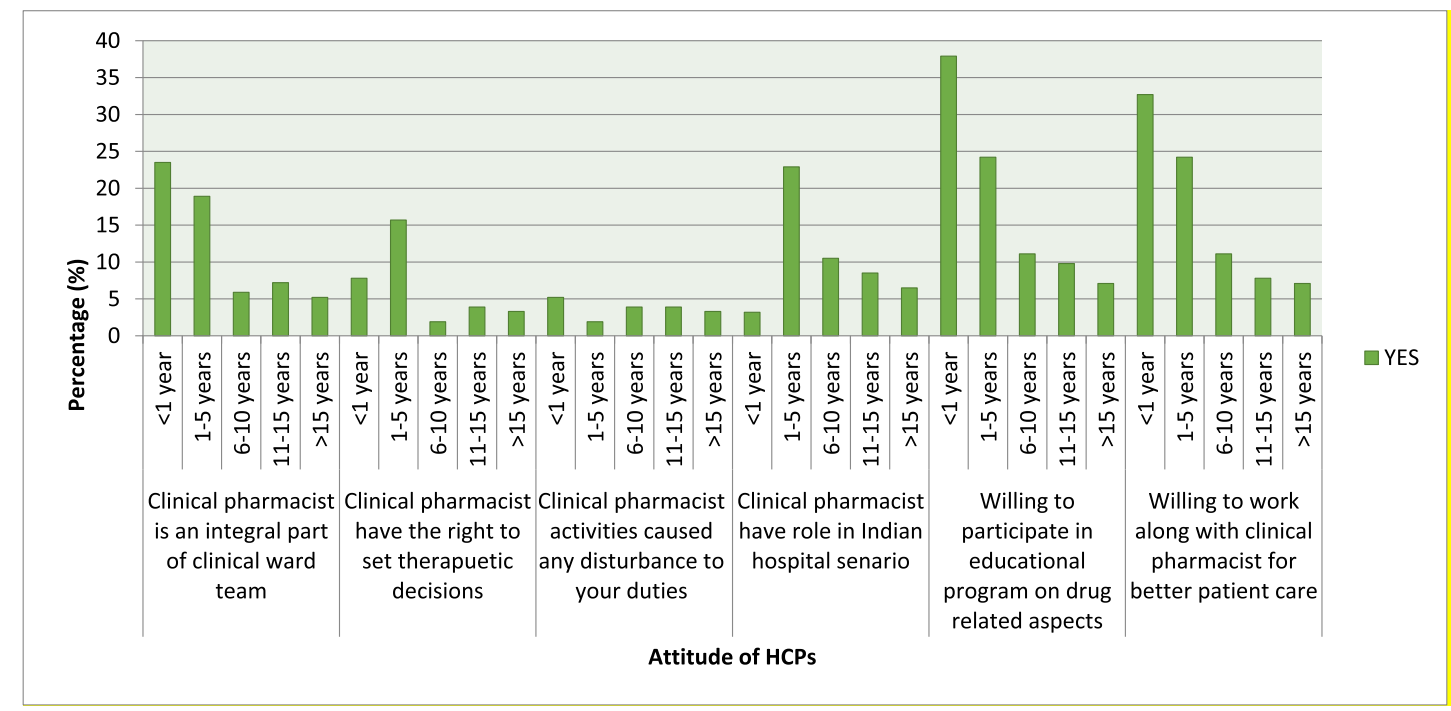

Fig. 2. Correlation of the year of experience with the attitude of professionals.

\section{Declaration of competing interest}

The authors declare that none of them has conflicts of interest regarding the publication of this paper.

\section{References}

1. American College of Clinical Pharmacy. Standards of practice for clinical pharmacists. Pharmacotherapy. 2014;34(8):794-797. Available from http://www.accp.com/ docs/positions/guidelines/StndrsPracClinPharm Pharmaco8-14.pdf.

2. Stringer Katherine, Curran Vernon, Asghari Shabnam. Pharmacists and family physicians: improving interprofessional collaboration through joint understanding of our competencies. Pharmaceutical Medicine and Outcomes Research. 2013;4:1-3.

3. Ma Carolyn SJ, Holuby R Scott, Bucci Lucy L. Physician and pharmacist collaboration: the university of hawai'i at hilo college of pharmacy - JABSOM experience. Hawaii Med J. 2010;69(3):42-44.

4. Connie Van, Costa Daniel, Mitchell Bernadette, Abbott Penny, Krass Ines. Development and validation of the GP frequency of interprofessional collaboration instrument (FICI-GP) in primary care. J Interprof Care. 2012;26:297-304.

5. Sabry Nirmeen A, Farid Samar F. The role of clinical pharmacists as perceived by Egyptian physicians. Int J Pharm Pract. 2014;22(5):354-359.

6. Zaidan Manal, Singh Rajvir, Wazaify Mayyada, Tahaineh Linda. Physician's perceptions, expectations, and experience with pharmacists at Hamad Medical Corporation in Qatar. J Multidiscip Healthc. 2011;4:85-90.

7. Almazrou Saja, Alnaim Lamya, Al-Kofide Hadeel. Perceptions, expectations and barriers of physicians towards working with clinical pharmacists in Saudi Arabia. Journal of Scientific Research \& Reports. 2015;6(5):404-415.

8. Varela Niurka María Dupotey, et al. What is the role of the pharmacist? Physicians' and nurses' perspectives in community and hospital settings of Santiago de Cuba. Braz J Pharm Sci. 2011;47(4):709-718.

9. Abu-Gharbieh Eman, Fahmy Sahar, Abdul Rasool Bazigha, Abduelkarem Abduelmula, Basheti Iman. Attitudes and perceptions of healthcare providers and medical students towards clinical pharmacy services in United Arab Emirates. Trop $J$ Pharmaceut Res. 2010;9(5):421-430.

10. Wilbur Kerry, Beniles Amina, Hammuda Arwa. Physician perceptions of pharmacist roles in a primary care setting in Qatar. Glob Health. 2012;8(12):1-4.

11. Ibrahim Osama Mohamed, Ibrahim Rana. Perception of physicians to the role of clinical pharmacists in United Arab Emirates (UAE). J Pharm Pharmacol. 2014;5:895-902.

12. Bilal Arebu Issa, Tilahun Zelalem, Beedemariam Gebremedhin, Ayalneh Belete, Hailemeskel Bisrat, Engidawork Ephrem. Attitude and satisfaction of health care providers towards clinical pharmacy services in Ethiopia: a post-deployment survey. J Pharm Policy Pract. 2016;9(7):1-14.

13. Kelly Deborah V, bishop Lisa, Young Stephanie, hawboldt John, Phillips Leslie, Montgomery Keough T. Pharmacist and physician views on collaborative practice: findings from the community pharmaceutical care project. CPJ/RPC. 2013;146(4):218-226.

14. Roland Nnaemeka Okoro, Mohammed Adamu Auwal. Hospital pharmacists' participation in multidisciplinary ward rounds: physicians' perceptions and attitudes. $\mathrm{Br} J$ Pharmaceut Res. 2015;5(5):319-327.

15. Li Xin, Huo Haiqin, Kong Wenjun, Fan Li, Wang Jingwen. Physicians' perceptions and attitudes toward clinical pharmacy services in urban general hospitals in China. Int $J$ Clin Pharm. 2014;36:443-450.

16. Ranelli PL, Biss J. Physicians' perceptions of communication with and responsibilities of pharmacists. Am Pharm Assoc. 2000;40(5):625-630.

17. Hassali MA, Awaisu A, Shafie AA, Saeed MS. Professional training and roles of community pharmacists in Malaysia: views from general medical practitioners. Malays Fam Physician. 2009;4(2):71-76. 